\title{
LOS PARLAMENTOS NACIONALES Y LA UNIÓN EUROPEA: EL MECANISMO DE ALERTA TEMPRANA
}

\author{
POR \\ ENRIQUE ÁLVAREZ CONDE \\ Catedrático de Derecho Constitucional \\ Universidad Rey Juan Carlos de Madrid \\ ALICIA E. LÓPEZ DE LOS MOZOS DÍAZ-MADROÑERO \\ Profesora de Derecho Constitucional \\ de la Universidad Rey Juan Carlos
}

\section{INTRODUCCIÓN}

Los resultados adversos de los referéndum francés y holandés ${ }^{1}$ condujeron a la Declaración de los Jefes de Estado y de Gobierno de

\footnotetext{
${ }^{1}$ Los resultados de estos referéndums han sido interpretados en diferentes claves políticas, como son la entrada futura de Turquía en la Unión Europea o la disminución de los servicios del Estado del Bienestar en determinados países. Al propio tiempo, se ha puesto en tela de juicio la propia institución del referéndum como mecanismo ad hoc para la ratificación de los Tratados de la UE. Pero lo cierto es que así como hay que respetar la voluntad de franceses y holandeses, también hay que tener en cuenta la voluntad de todos aquellos países, que, además, son la mayoría, ya han ratificado la Constitución Europea, algunos de ellos, como España y Luxemburgo, también a través de referéndums nacionales.
} 
los Estados miembros de la Unión Europea sobre la ratificación del Tratado por el que se establece una Constitución para Europa, acordada en el Consejo Europeo de los días 16 y 17 de junio del 2005, en la cual se acuerda emprender "una reflexión común", acordando que el calendario de ratificación se adapte a los nuevos acontecimientos. Esta declaración, que no implica una suspensión formal del proceso de ratificación, ha sido interpretada desde diversas posturas políticas y científicas. Pero lo cierto es que, aunque el proceso de ratificación de la Constitución europea se dilate en el tiempo ${ }^{2}$, la cuestión, con ser importante, no implica una desaparición del Ilamado Derecho Constitucional europeo ${ }^{3}$. Y ello por dos razones:

- Porque el actual contenido del Proyecto de Constitución europea se encuentra en gran parte en vigor (más del $80 \%$ ).

- Porque el contenido del actual Proyecto de Constitución difícilmente va a verse alterado en sus principios sustanciales, convirtiéndose, en todo caso, en un texto de referencia de trascendental importancia.

Por otro lado, las constituciones de los Estados miembros, y aqueIlas normas que integran sus respectivos bloques de constitucionalidad, están Ilamadas a desempeñar un importante papel en el proceso de construcción europea, máxime si se produce la llamada "europeización" de las mismas, como ha sucedido en la mayor parte de los países tras la ratificación del Tratado de Maastrich. De este modo, la existencia de una Constitución europea supone la formalización de un espacio constitucional europeo donde las diferentes constituciones de los Estados miembros continúan siendo hoy por hoy el centro de gravedad. Con la Constitución europea se reconoce una doble legitimidad: a los Estados y a los pueblos, realizándose esta última a costa

2 Las previsiones apuntan hacia los años 2009 o 2010 como fechas clave para la ratificación definitiva, evitándose cualquier ampliación nueva con anterioridad. Ello supondrá, necesariamente, la convocatoria previa, una vez celebradas las elecciones presidenciales francesas del 2007, de una nueva Conferencia Intergubernamental, que habrá de introducir algunos cambios, los cuales pueden realizarse con el sosiego necesario. Entre ellos, el más significativo puede ser la desaparición total de la Parte III, la cual apenas fue debatida en la Convención, y de no pocos Protocolos y Declaraciones. De este modo, la futura Constitución Europea quedaría reducida, sustancialmente y con las modificaciones oportunas, a las Partes I y II, que son las que tienen un auténtico contenido constitucional, siendo sus preceptos objeto de un desarrollo normativo posterior.

3 Cfr., por todos, P. HABERLE: "Derecho constitucional común europeo», Revista de Estudios Políticos, núm. 79 y «El Estado constitucional», México, 2001. 
del reconocimiento de las regiones como integrantes de la Unión Europea.

La existencia de un constitucionalismo europeo no es cuestión nueva en los actuales planteamientos dogmáticos. Incluso podría decirse que la existencia de un ordenamiento jurídico común europeo es coetánea con los distintos intentos de creación de una organización supranacional europea, cuyos antecedentes históricos se remontan a hace ya varios siglos. ${ }^{4}$

La creación de una estructura supranacional en el ámbito europeo, a partir del Tratado de Roma de 1957, coincide, en el tiempo y en el espacio, con el último ciclo del constitucionalismo contemporáneo. Es decir, ya se había producido, al menos en algunos países, la instauración de los nuevos principios informadores $y$, consecuentemente, su incorporación a ese Derecho Constitucional material común europeo que, es, por tanto, previo incluso a la existencia de los Tratados Comunitarios y de las propias Comunidades Europeas.

Junto a ello, hay que señalar que el proceso de ampliación de la Unión Europea (cuyo Tratado de adhesión de los diez últimos países fue autorizado por España a través de la Ley orgánica 12/2003, de 24 de

${ }^{4}$ Cfr., por todos, P. CralG: "Constitutions, Constitucionalism and the European Union», en European Law Journal, 7, 2, 2001; F. MERLI: "Hacia una Constitución común europea, Revista de Derecho Comunitario europeo, núm., 9, 2001; J. A. CARRILLO SALCEDO: "Hacia una constitución para los ciudadanos europeos», Revista Andaluza de Administración Publica, núm. 45, 2002; C. RUIZ MIGUEL: "La problemática transformación del Derecho Constitucional europeo", en Anuario de Derecho Constitucional y Parlamentario, núm. 14, 2002; X. VIDAL FOLCH: "La Constitución europea. Norma legal, política real e impacto de la guerra de Irak» en Claves de la Razón Practica, núm. 135, Madrid 2003; R. M. Yoghis CARRASCO: "Constitución europea: un concepto prematuro", Valencia 2000; P. A. SAENZ DE SANTAMARÍA: "Hacia una Constitución europea», La Ley, núm. 6116, 28 octubre del 2004, quien habla de un transito de una Constitución en sentido material a otra en sentido formal. Cfr., asimismo, A. PIzorRusso: "El difícil camino de la Constitución europea» y F. J. MATIA PORTILLA: "¿Hay una Constitución europea?", ambos en el Libro Homenaje a F. Rubio Llorente "La democracia constitucional», Madrid 2002. Finalmente, L. M. DíEZ PICAZO: "Constitucionalismo de la Union Europea», Madrid 2002, quien señala, en el Prólogo, que «hablar de constitucionalismo equivale a hablar de los problemas jurídicopolíticos básicos. Poner en conexión constitucionalismo y Unión Europea permite, así, percatarse de hasta que punto la integración europea incide sobre esas cuestiones fundamentales de todo ordenamiento; y ello tanto porque la integración europea altera el significado de algunas nociones claves -piénsese, verbigracia, en la soberanía o en la ciudadanía- como porque crea serias lagunas que habrán de ser colmadas, en aspectos cruciales de la organización y el funcionamiento del poder". 
octubre) y la uniformidad creada por los distintos operadores jurídicos (especialmente el TEDH y el TJCE) va a suponer una profundización en ese Derecho constitucional material común. Ya no se trata solo de principios materiales comunes sino de la existencia de instituciones comunes, y del establecimiento de una jurisprudencia común que crea relaciones jurídicas comunes, que afectan a los propios ciudadanos europeos, y que suponen, a la postre, una definitiva transición de un Derecho Constitucional material común a un Derecho Constitucional formal común.

Pero al propio tiempo que se produce esta situación, nos encontramos ante un proceso de transformación radical del Estado contemporáneo, cuya evolución futura es todavía difícil de prever. Cuestiones tales como la globalización, la mundializacion, el impacto de las nuevas tecnologías, la llamada sociedad de la información, etc... ${ }^{5}$ hacen que las estructuras del estado nacional no resulten ya las más apropiadas para desarrollar las funciones que tiene actualmente encomendadas y que éste se haya desprovisto de sus características inicialmente configuradoras (la soberanía, la emisión de moneda, el propio territorio.... ${ }^{6}$. Sin duda alguna, todos estos procesos tienen consecuencias negativas, que pueden afectar a nuestros sistemas normativos. Pero, también es cierto, que se configuran como un hecho irreversible, pues la rapidez y facilidad en la circulación de ideas, de mercancías y de capitales, la existencia, en definitiva, de un espacio comunicativo compartido por todo el mundo, no parece tener vuelta atrás. Parece que la mundializacion económica, informativa y comercial ha dejado a la política reducida en sus enclaves territoriales, sin que aun hayamos sido capaces de crear instituciones o espacios de gobernación de la globalización. Por todo ello, la dogmática jurídica que había servido de base para proporcionar una explicación más o menos racional y coherente del estado constitucional, se convierte en insuficiente e inoperante, sin que hayan aparecido nuevas categorías dogmáticas que proporcionen una expli-

5 Sobre estas cuestiones, cfr., entre otros, R. DHAL: "La democracia. Una guía para los ciudadanos", Madrid 1999; A. GIDDENS: "Un mundo desbocado. Los efectos de la globalización en nuestras vidas.", Madrid 2000; G. SARTORI: "La democracia después del comunismo", Madrid 1993; F. FuKUYAMA: "El fin de la historia y el ultimo hombre», Madrid 1992; J. HABERMAS: "La inclusión del otro", Madrid 1999 y "La constelación posnacional», Barcelona 2000; S. P. HUNTINGTON: «El choque de las civilizaciones y la configuración del orden mundial», Madrid 1997; G. MAESTRO: "Globalización y Constitución débil», en Teoría y Realidad Constitucional, núm. 7, 2001.

6 Cfr., a este respecto, entre nosotros, P. de VEGA GARcía: "La mundialización y el Derecho Constitucional», Revista de Estudios Políticos, núm. 123, pp. 57 y ss 
cación racional de las transformaciones a que estamos asistiendo. Por otro lado, también resulta impensable admitir que las organizaciones supraestatales que van surgiendo y consolidándose entre nosotros prescindan, de forma absoluta, de alguno de los elementos configuradores del Estado constitucional. No se trata de una defensa a ultranza del estado-nación, ni una apología del viejo estatalismo, sino simplemente de mantener las estructuras y categorías conceptuales que, hoy por hoy, resultan imprescindibles en la consolidación y profundización de los sistemas democráticos y del Estado de Derecho.

La Constitución europea no es producto de un auténtico poder constituyente europeo, ni supone la creación ordenamiento jurídico propio y radicalmente diferente del anterior, con el cual no presenta elementos de auténtica ruptura normativa. Es más, la Constitución europea debe ser calificada como una continuidad del Derecho comunitario anterior, pues el proceso de construcción europea tiene un carácter abierto, flexible y dinámico que no se cierra definitivamente con la aprobación de la Constitución europea.

Por otro lado, no debemos olvidar que el proceso de constitucionalización no radica únicamente en la función constituyente que desempeña respecto de toda organización internacional el respectivo Tratado constitutivo, sino en incorporar a este aspecto funcional un factor cualitativamente diferente, como es la idea de que existe una Norma Fundamental que dota al ordenamiento jurídico en cuestión de una rigidez formal, pues se encuentra provista de una supremacía normativa, pudiendo incluso contemplarse la intangibilidad de alguno de sus contenidos. Si todo ello es cierto desde la lógica del Estado constitucional, también es posible afirmar que la aprobación de la Constitución europea supone, al menos en cierta medida, la constitucionalización de la Unión, que ya había sido anunciada por el propio Tribunal de Justicia. ${ }^{7}$

Ello puede plantear el problema de las relaciones entre la Constitución Europea por un lado, y las Constituciones de los Estados miembros por otro, algunos de los cuales, debido a su estructura política descentralizada, también permiten la existencia de Constituciones internas y propias de las entidades descentralizadas. Así, podemos llegar a la conclusión de que si todas las constituciones de los Estados miembros

7 C. Rodríguez; "La constitucionalización de la Unión Europea», Revista de Derecho Comunitario Europea, núm. 16, 2003, pp. 893 y ss.; J. L. QUERMONNE: "L'Union europeenne: objet ou acteur de sa Constitution? Essai sur la portee d' une politique institutionnelle á longue terme " en Revue francaise de science politique, 2004 ; AA.VV.: "Una Constitución para la ciudadanía de Europa», Pamplona 2004. 
son derecho comunitario, son constituciones europeas, también todas las instituciones de los Estados serán instituciones europeas, y por lo tanto lo serán los Parlamentos nacionales y los regionales. El tema ha sido abordado desde diferentes posiciones doctrinales, utilizándose categorías tales como la de constitución abierta, mutación constitucional, constitucionalismo dual, federalismo intergubernamental, constitución red, metaconstitución, inclusión constitucional, concepción funcional e instrumental de la idea de Constitución, y un largo etcétera, ${ }^{8}$ sin que, hoy día, sea posible hablar de la existencia de un minimum conceptual, comúnmente admitido entre la doctrina científica, que únicamente parece de acuerdo en revisar los mitos dogmáticos establecidos. Todo ello, sin olvidar que las Constituciones nacionales están todavía llamadas a desempeñar un importante papel en el proceso de construcción europea, máxime si se produce la llamada "europeización» de las mismas. Así pues, la futura aprobación de una Constitución europea supone la formalización del espacio constitucional europeo, cuya existencia, al menos desde un punto de vista material, es anterior a la misma. Espacio constitucional europeo en el cual las Constituciones de los diferentes Estados miembros han de seguir desempeñando un papel crucial, pues continúan siendo el centro de gravedad del mismo.

Por otro lado, hay que tener en cuenta que la formalización definitiva del Derecho Constitucional europeo ha de afectar a las propias instituciones europeas y nacionales. La peculiar estructura del ejecutivo comunitario, la consideración del Tribunal de Justicia como auténtico Tribunal Constitucional de la Unión Europea, la existencia de otros importantes órganos, como el Banco Central Europeo y el Banco de In-

8 A ello no son ajenas las Ilamadas cláusulas europeas o de garantía estructural existentes en algunas Constitucionales nacionales, como es el caso del art. 23.1. de la Constitución alemana, reformado en 1992, con ocasión de la ratificación del Tratado de Maastrich, que expresamente señala: "Con el fin de alcanzar una Europa unida, la República Federal de Alemania colabora en el desarrollo de la Unión Europea, la cual se halla vinculada a los principios de democracia, estado de derecho, social y federativo, así como al principio de subsidiariedad, otorgando una protección de los derechos fundamentales esencialmente comparable a la otorgada por esta Ley Fundamental». Cfr., a este respecto, entre nosotros, los planteamientos efectuados por P. CRUZ VILLALÓN: "Constitución Europea y Constituciones nacionales» en el libro colectivo Comentarios a la Constitución Europea, cit., vol. I, Valencia 2004 y I. Pernice y F. C. MAYER: "De la Constitution composée de l'Europe», en $R e$ vueTrimestrielle de Droit Européene, 36, 4, 2000; K. LENAERTS y P. VAN NufFEL: "Constitutional law of the Eurpean Union ", London 1999; L. FAVOREAU y H. OberdofF: "Droit Constitutionnell et Droit Communaitaire", en Revue du Marche Commun et de I'Union Eurpeene , 435, 2000. 
versiones, ambos dotados de personalidad jurídica propia y diferenciada de la Unión, son ejemplos relevantes. El Parlamento Europeo ya manifestó su preocupación por el desequilibrio producido como consecuencia del papel atribuido a las instituciones europeas, generando un déficit democrático ${ }^{9}$, y estableciendo que para solucionar este problema era necesario "reforzar el componente parlamentario en el sistema institucional europeo" ${ }^{10}$.

A la hora de analizar el papel de los Parlamentos nacionales en el ordenamiento europeo, no podemos reproducir, aquí y ahora, las teorías sobre la crisis de los Parlamentos, que se inician desde mediados del siglo XIX, sino al contrario, poner relieve que, con la existencia de un Derecho Comunitario, se abre para los Parlamentos nacionales, despojados históricamente por los gobiernos de sus funciones clásicas, un nuevo periodo que ha de conducir, necesariamente, a una transformación radical de su organización y funcionamiento, convirtiéndose en instancias representativas capaces de dar una respuesta rápida a los problemas que plantea el Estado contemporáneo ${ }^{11}$.

Los Parlamentos nacionales son una de las más claras fuentes de legitimidad de la Unión ${ }^{12}$, y participan en la Unión europea de tres maneras distintas (CONV 67/02):

9 NeUnReither, K.: "The dual legitimacy of European Union and democratic deficit", en The Democratic deficit of European Union:Towards closer coopetation between the European Parliament and the national Parliaments, Gobermente and Opposition 29, 1994, pp. 311 y ss.

10 Así lo manifiesta en la Resolución del Parlamento Europeo de 7 de febrero de 2002, sobre las relaciones entre el Parlamento Europeo y los Parlamentos nacionales.

11 Sobre estas cuestiones, Cfr. los clásicos estudios de W. BAGEHOT: "The English Constitution», Cornell University Press, Ithaca, Nueva Cork, 1995; B. CRICK: "The reform of Parliament", Cox and Wyman, Londres 1970; H. KELSEN: "Escritos sobre la democracia y el socialismo"; Debate, Madrid 1988, etc. Por lo que se refiere a nuestro Parlamento, cfr. las interesantes propuestas realizadas por E. GUERRERO: «Reformas para revitalizar el Parlamento español», Fundación Alternativas, Madrid 2005. Pensemos, a modo de ejemplo, en la necesidad de que todos los Parlamentos nacionales y regionales estén dotados de las estructuras administrativas necesarias para poder ejercer sus funciones en relación con la Unión Europea (creación de una Oficina de Información y Documentación, semejante a la que existe en el Congreso USA, existencia de una Oficina Presupuestaria, creación de una Oficina específicamente europea, presencia de los Parlamentos en las sedes comunitarias, etc.).

12 Rubio NúÑEz, R. y Martínez SierRA, J. M.: "La reforma institucional de la Unión Europea: el camino de la legitimidad en Europa", Debates constitucionales. Revista electrónica de Derecho Constitucional, Universidad de Oviedo, n. ${ }^{\circ}$ 1, julio-1999. 
- Función legislativa: en la elaboración y aplicación del Derecho de la Unión, tanto en el derecho primario (modificación de los tratados y acuerdos de adhesión), como en el derecho derivado (decisiones y actos del Consejo).

- Función de control: ejercen control político sobre las posiciones adoptadas por sus gobiernos respectivos en el Consejo.

- Función de cooperación: establecen relaciones de cooperación con otros parlamentos de la Unión.

En cualquier caso, y para llevar a cabo sus funciones, los Parlamentos nacionales deben estar adecuadamente preparados en los temas comunitarios, ya que es allí donde residen los intereses de los ciudadanos a los que representan ${ }^{13}$, debiendo dotarse, a tal efecto, de las estructuras necesarias. Durante los trabajos de la Convención Europea, alguno de sus miembros ya señaló la importancia de destacar aún más el cometido de los Parlamentos nacionales y el hecho de que su implicación en temas comunitarios acercaría más a los ciudadanos a la Unión. La atribución de las competencias nacionales a favor de la Unión Europea trae como consecuencia que los Parlamentos nacionales pierdan parte de sus competencias legislativas al formar parte éstas de la Unión ${ }^{14}$.

Antes de la creación de este sistema, los Parlamentos solo podían intervenir en el ámbito de la Unión sobre textos cerrados, no teniendo de este modo un papel influyente. Su única función venía a ser la creación o modificación de leyes para poder adaptarlas a la normativa europea, consecuencia, en la mayoría de los casos de la aprobación de directivas comunitarias. Así se manifestó en la Convención donde se llegó a afirmar que los Parlamentos nacionales se limitan a desempeñar un mero papel de registro de las directivas comunitarias (CONV 67/02).

En cualquier caso el sistema de alerta temprana supone un importante paso adelante y se deriva en parte del hecho de que a los Parlamentos nacionales se les reconoce:

- el derecho a la información y cooperación.

- el derecho a garantizar el correcto uso del principio de subsidiariedad.

13 GIL IBÁÑEZ, A. J.: "Los Parlamentos nacionales y la Unión Europea: ¿primer o cuarto poder?", en la obra El gobierno de Europa. Diseño institucional de la Unión Europea, dirigida por BeneYto PéREZ, J. M.: Dykinson, Madrid, 2003, p. 195.

${ }^{14}$ Mangas Martín, A.: La Constitución Europea, lustel, Madrid, 2005, p. 135. 


\section{ANTECEDENTES DEL SISTEMA DE ALERTA TEMPRANA}

El sistema de alerta temprana se establece con el fin de que los Parlamentos nacionales, y en su caso, regionales, puedan llevar a cabo precisamente la función de controlar la correcta aplicación del principio de subsidiariedad, lo que a su vez no sería posible si no se respetase y llevase a la práctica adecuadamente el derecho de información de los Parlamentos nacionales respecto a determinados actos de las instituciones. Así queda establecido en el Protocolo 1 sobre la función de los Parlamentos nacionales en la Unión Europea, donde, en su título I, Información a los Parlamentos nacionales, se establece que los documentos de consulta de la Comisión, el programa legislativo anual, las propuestas de actos legislativos, así como cualquier otro instrumento de programación legislativa o estrategia política, será trasmitido para su conocimiento, a los Parlamentos nacionales.

El artículo I-11.3 del Proyecto de Constitución Europea, referente al principio de subsidiariedad, establece en su párrafo segundo que "...Los Parlamentos nacionales velarán por el respeto a dicho principio con arreglo al procedimiento establecido en el mencionado Protocolo". Se refiere, por tanto, al Protocolo II: Sobre la aplicación del principio de subsidiariedad y proporcionalidad, protocolo en el que se desarrolla el mecanismo de alerta temprana, consistente en el poder que tienen los Parlamentos nacionales de controlar los proyectos de actos legislativos de la Comisión, en relación a la correcta aplicación o no del principio de subsidiariedad, mediante la emisión de un dictamen motivado al respecto. Este sistema, definido como mecanismo de control político previo, se aplicará, en principio, cuando la Constitución europea entre en vigor, pero, a nuestro criterio, nada impide ir poniendo en la práctica el mismo a través de dos procesos de reforma:

a) Mediante las oportunas reformas de la actual legislación comunitaria que afectarían, al menos, a la normativa referente aquellos órganos titulares de la capacidad para dictar proyectos de actos legislativos (Parlamento, Comisión, Tribunal de Justicia, Banco Central Europeo y Banco Europeo de Inversiones - art. 3 del Protocolo de Subsidiariedad), pudiendo aprovecharse las posibilidades que permite, al menos en algunos casos, la actual legislación vigente ${ }^{15}$.

15 A este respecto son interesantes los artículos 123 y 124 del Reglamentos del Parlamento Europeo:

Artículo 123 : Intercambio de información, contactos y facilidades recíprocas

1. El Parlamento mantendrá periódicamente informados de sus actividades a los Parlamentos nacionales de los Estados miembros. 
b) A través de la legislación interna de los Estados miembros. Por lo que se refiere al caso español, además de una adecuada reforma de la Constitución, se debería proceder a la modificación de la legislación estatal y autonómica afectada, como pudieran ser, a modo de ejemplo, los Estatutos de Autonomía, los Reglamentos de las Cámaras Legislativas, los Reglamentos de los Parlamentos autonómicos, etc...

Pero previo a la aparición de estos protocolos, y a la consecuente aparición de este sistema, el camino a recorrer ha sido largo.

Actualmente la función de control de los Parlamentos nacionales respecto a los temas de la Unión Europea se encuentra regulada en el Protocolo anejo al Tratado de Ámsterdam de 1997. Pero fue el Tratado de Maastricht en 1992, el que por primera vez plasmó el papel de los Parlamentos nacionales en la Unión Europea (con anterioridad a este tratado no se menciona a los Parlamentos nacionales en los textos europeos), estableciendo que los distintos gobiernos velarían para que éstos recibieran las propuestas de la Comisión con una antelación suficiente para ser examinadas. Sin embargo los términos usados son muy genéricos: "velar", "propuestas legislativas de la Comisión", sin especificar nada más. Maastricht vino sin duda a aportar un valor añadido en el proceso hacia la consecución de un espacio político y jurídico de participación activa en la tarea de edificación de la Unión Europea. Pero aún así, el carácter genérico de la Declaración y la ausencia de fuerza vinculante de la misma le dio un carácter más simbólico que efectivo, lo que produjo una insatisfacción a los defensores de esta vía, y la necesidad de dar un paso más.

2. La Conferencia de Presidentes podrá otorgar mandato al Presidente para que negocie facilidades para los Parlamentos nacionales de los Estados miembros, si procede con carácter recíproco, y para proponer cualesquiera otras medidas destinadas a facilitar los contactos con los Parlamentos nacionales.

Artículo 124: Funciones de la Conferencia de Presidentes

1. La Conferencia de Presidentes asumirá las funciones que le encomienda el Reglamento.

2. La Conferencia de Presidentes resolverá sobre la organización de los trabajos del Parlamento y sobre los asuntos relacionados con la programación legislativa.

3. La Conferencia de Presidentes será el órgano competente en los asuntos vinculados a las relaciones con las demás instituciones y órganos de la Unión Europea, así como con los Parlamentos nacionales de los Estados miembros. La Mesa designará a dos Vicepresidentes, que se encargarán de la puesta en práctica de las relaciones con los Parlamentos nacionales. Deberán informar a la Conferencia de Presidentes periódicamente acerca de sus actividades al respecto. 
Posteriormente, esto fue modificado en el Protocolo 9 del Tratado de Ámsterdam relativa al "Cometido de los Parlamentos nacionales en la Unión Europea», introduciendo novedades importantes:

- la mera declaración donde se señalaba la conveniencia de fomentar la participación de los Parlamentos nacionales, se transforma en un deber vinculante;

- se establecen cuáles son las propuestas que deben transmitirse a los Parlamentos nacionales:

- Propuestas legislativas de la Comisión

- Propuestas de la Comisión en el ámbito del Tercer pilar (cooperación policial y judicial)

- Los libros blancos y verdes y las comunicaciones.

- se establece un plazo de seis semanas para que los Parlamentos nacionales examinen dichas propuestas comunitarias, antes de que el Consejo pueda tomar algún acuerdo.

En este Protocolo se da cabida, a diferencia del ámbito establecido en el Protocolo n. ${ }^{\circ} 2$ del Proyecto de Constitución Europea, que se ciñe al principio de subsidiariedad como posteriormente veremos, a los actos normativos del Art. 249 de la versión consolidada del Tratado Constitutivo de la Comunidad Europea (reglamentos, directivas, decisiones, recomendaciones y dictámenes), así como demás actos normativos comprendidos dentro del ámbito de la cooperación policial y judicial ${ }^{16}$.

Con posterioridad al Tratado de Ámsterdam, la Declaración n. ${ }^{\circ} 23$ del Tratado de Niza también reflejó que uno de los temas de reflexión debería ser la función de los Parlamentos nacionales en la arquitectura europea (CONV 67/02). Por último, en la Declaración de Laeken se plantean cuestiones similares. Se indica que el papel de los Parlamentos nacionales, y por tanto también de las relaciones entre el Parlamento Europeo y los Parlamentos nacionales, es uno de los cuatro temas que hay que colocar en el centro de un amplio debate, destinado a convocar una nueva Conferencia Intergubernamental. De esta forma vuelve a primer plano un tema que nunca ha dejado de serlo: el déficit democrático, debido a que hasta este momento, se advierte un creciente malestar de los Parlamentos nacionales por los insuficientes progresos realizados hasta ahora en materia de control democrático del proceso

16 Prieto Gutiérrez, M. G.: «Relaciones entre el Parlamento Europeo y los Parlamentos Nacionales», en la obra Comentarios a la Constitución Europea, dirigido por Álvarez Conde, E. y Garrido Mayol, V.: libro I, Tirant lo Blanch, Valencia, 2004, p. 808. 
de integración. Por ello podemos establecer el hecho de que el significado de que los Parlamentos nacionales se vean incluidos en la construcción europea se debe en parte al «desgaste, insuficiencia o inadecuación " ${ }^{17}$ de las funciones del Parlamento Europeo.

Sin embargo, frente a este sistema y como señalan algunos autores $^{18}$, continúan existiendo imprecisiones que a día de hoy hacen que el mecanismo no sea del todo eficaz. Por ejemplo:

- no está claro qué órgano es el encargado de trasmitir esas propuestas y documentos a los Parlamentos nacionales, aunque por regla general son sus propios gobiernos;

- el hecho de que esta acción se deje precisamente en manos de los respectivos gobiernos ha generado numerosas críticas debido a los retrasos que se vienen produciendo en dichas entregas, y la consecuente reducción del plazo de seis semanas, de por sí ya muy breve, del que disponen los Parlamentos nacionales.

Debería, por tanto, regularse en los reglamentos de las respectivas cámaras el procedimiento a seguir por el órgano encargado de trasmitirles esa información, de modo que éstas no fueran las perjudicadas. Uno de los modos más extendidos hasta el momento de reforzar el control parlamentario nacional interno ha sido la creación de una Comisión especializada en los Asuntos de la Unión Europea, cuya composición, funciones y eficacia varía de un país a otro. En España la Comisión Mixta, en Bélgica, Comisiones legislativas sectoriales y en Luxemburgo, la Comisión de Asuntos Europeos, son algunos ejemplos. Otra alternativa es por ejemplo el caso británico, donde la Cámara de los Lores elabora un número concreto de informes, pero de alto interés y profundidad con el objeto de que sean tenidos en cuenta.

\section{a) La COSAC y la Comisión Mixta para la Unión Europea.}

Todo este mecanismo se completa con las funciones llevadas a cabo por una serie de órganos. Así, en el mismo Protocolo anejo del Tratado de Ámsterdam se establecen las reglas de actuación de la CO$S A C$, Conferencia de Órganos Especializados en Asuntos Europeos,

17 LiÑÁn Nogueras, D. J.: «El Parlamento Europeo y el papel de los Parlamentos nacionales", en la obra El gobierno de..., op. cit., p. 180.

18 Delgado-Iribarren García-Campero, M.; "La participación en la Unión Europea de los Parlamentos nacionales en la Constitución Europea», en la obra Comentarios a la..., op. cit., p. 769. 
órgano que se constitucionaliza en este Tratado. Las funciones que lleva a cabo están directamente relacionadas con el papel de los Parlamentos nacionales.

Así, tal y como se establece en el Protocolo, la COSAC, creada el 16 y 17 de noviembre de 1989, basándose principalmente en proyectos de textos normativos que previamente los representantes de los Estados miembros le han transmitido (en función de la naturaleza de los asuntos a tratar), podrá dirigir a las Instituciones de la Unión Europea las contribuciones que juzgue convenientes. También podrá llevar a cabo las siguientes funciones:

- estudiar cualquier propuesta o iniciativa legislativa relacionada con la creación de un espacio de libertad, seguridad y justicia, siempre y cuando pueda tener algún tipo de consecuencia directa sobre los derechos y libertades de las personas, e informando adecuadamente al Parlamento Europeo, al Consejo y a la Comisión de lo mismo;

- dirigir a cualquiera de las instituciones anteriormente mencionadas, cualquier aportación que estime oportuna, sobre las actividades legislativas que venga desarrollando al Unión, con especial interés todo aquello que esté relacionado con el principio de subsidiariedad.

En definitiva, su misión principal consiste en mejorar la información de los Parlamentos nacionales mediante el intercambio sistemático de los textos que se adoptan. En cualquier caso hay que tener en cuenta que la labor llevada a cabo por la COSAC no vincula a los Parlamentos nacionales ni prejuzga su posición. Así lo establece el apartado II "Conferencia de Órganos especializados en Asuntos Europeos" del Protocolo sobre el cometido de los Parlamentos nacionales en la Unión Europea, anejo al Tratado de Ámsterdam. En la actualidad podemos decir que la COSAC es un órgano consultivo de carácter atípico.

Además de la COSAC, y ya desde un ámbito nacional, uno de los modos más extendidos de reforzar el control de los Parlamentos nacionales, ha sido la creación de una comisión especializada en asuntos de la Unión Europea. Así se crea en España la Comisión Mixta para la Unión Europea ${ }^{19}$, comisión permanente y no legislativa, regulada me-

19 Viciano PAStOR, R.: "La Comisión Mixta para la Unión Europea: algo más que un mero instrumento de control parlamentario", en Parlamento y Constitución, 1999. 
diante la Ley 8/1994, de 19 de mayo ${ }^{20}$, así como en la Resolución de las Mesas del Congreso y del Senado de 21 de septiembre de 1995. La Comisión Mixta del Congreso de los Diputados y del Senado, denominada Comisión Mixta para la Unión Europea, se establece con el fin de que las Cortes Generales tengan la participación adecuada en las propuestas legislativas elaboradas por la Comisión Europea y dispongan, en general, de la más amplia información sobre las actividades de la Unión Europea. Está formada por diputados y senadores, garantizando la presencia de todos los grupos parlamentarios, y presidida por el presidente del Congreso de los Diputados, o en su defecto, por el diputado o senador en quien éste delegue, aunque la regla general es que esté presidida por un miembro del grupo mayoritario de la oposición en el Congreso. Las labores que desarrolla consisten en preguntas, comparecencias y proposiciones no de ley, todo ello en relación con lo establecido en el protocolo al que anteriormente nos hemos referido. En concreto podemos señalar, entre otras, las siguientes:

- conocer la publicación de los decretos legislativos promulgados en base al derecho derivado,

- informarse o examinar determinadas propuestas legislativas de la Comisión,

- Recibir, a través del Gobierno, las propuestas legislativas de la Comisión Europea, con antelación suficiente para su información o para que puedan ser examinadas.

- Celebrar debates sobre una propuesta legislativa concreta en el seno de la Comisión y solicitar, si se considera oportuno, al Presidente de cualquiera de ambas Cámaras la celebración de un debate en el Pleno respectivo con el mismo fin, participando el Gobierno en ambos casos.

- Recibir del Gobierno la información que obre en su poder sobre las actividades de las instituciones de la Unión Europea.

- Ser informada por el Gobierno de las líneas inspiradoras de su política en el seno de la Unión Europea, así como de las decisiones y acuerdos del Consejo de Ministros de la Unión Europea.

20 La Exposición de Motivos de esta Ley señala lo siguiente: «Los gobiernos de los Estados miembros velarán, entre otros aspectos, porque los Parlamentos Nacionales puedan disponer de las propuestas legislativas de la Comisión con la antelación suficiente para información o para que puedan ser examinadas». Es decir, podemos afirmar que el sistema de alerta temprana tiene sus antecedentes en este sistema de Comisión Mixta. 
- Elaborar informes sobre aquellas cuestiones relativas a la actividad de la Unión Europea que pueda considerar de interés.

- Establecer relaciones de cooperación con los órganos adecuados de los restantes Parlamentos de los países miembros de la Unión Europea y del Parlamento Europeo.

- Mantener relaciones de recíproca información y colaboración con las Comisiones existentes en otros Parlamentos nacionales de Estados miembros de la Unión que tengan competencias similares a las de la Comisión Mixta, así como con las correspondientes Comisiones del Parlamento Europeo.

Para ello, en la Resolución de las Mesas del Congreso de los Diputados y del Senado, de 21 de septiembre de 1995, sobre desarrollo de la Ley 8/1994 se establece, en su apartado primero, que cuando la Comisión Mixta reciba una propuesta legislativa de la Unión Europea, "cualquier grupo parlamentario podrá solicitar la celebración de un debate sobre dicha propuesta en el seno de la Comisión, o la ampliación, en su caso, de la información recibida por el Gobierno".

En definitiva, todas sus funciones derivan de lo establecido en el protocolo anejo al Tratado de Ámsterdam, donde se establece el deber de informar a los Parlamentos nacionales de los Estados Miembros. La más importante, por su relación con este tema, es el hecho de que los Parlamentos nacionales de los Estados miembros deben recibir puntualmente todos los documentos de consulta de la Comisión, es decir, libros blancos y verdes entre otros, como así lo establece el apartado I "Información a los parlamentos nacionales de los Estados miembros" del Protocolo sobre el cometido de los Parlamentos nacionales en la Unión Europea, anejo al Tratado de Ámsterdam. Además, se añaden otros dos apartados en los que se hace referencia al hecho de que, por un lado, las propuestas legislativas de la Comisión han de ser comunicadas con la suficiente antelación a los respectivos gobiernos de los Estados miembros, con el fin de que las Cámaras los reciban convenientemente; y por otro, se establece que, salvo en casos excepcionales por motivos de urgencia, el plazo entre el momento en que la Comisión transmite al Parlamento Europeo y al Consejo "una propuesta legislativa, o una propuesta de una medida que deba adoptarse en virtud del Titulo VI del Tratado de la Unión Europea" y la fecha de inclusión de la citada propuesta en el orden del día del Consejo, será de seis semanas.

De lo anterior es posible concluir que, si tenemos en cuenta el actual Protocolo del Tratado de Ámsterdam, aunque la Constitución europea 
no entre en vigor, y por tanto tampoco los protocolos, (o en el tiempo que resta hasta que se produzca esta entrada en vigor) el sistema podría llegar a desarrollarse si así lo decidiesen los Estados miembros, y mediante el consecuente desarrollo su legislación nacional en este sentido, respetando en todo caso el Derecho comunitario, el cual debería ser objeto de alguna modificación en el sentido apuntado anteriormente. De esta forma se otorgaría a los Parlamentos nacionales la posibilidad de llevar a cabo esta colaboración con el Parlamento Europeo sin esperar a la entrada en vigor de la Constitución europea.

Esta modificación legislativa podría llevarse a cabo respecto a la Ley 8/1994. Actualmente dicha ley establece que la Comisión, como representante de la Cámaras y por tanto del Parlamento nacional, ha de recibir, a través del Gobierno, las propuestas legislativas de la Comisión Europea, con antelación suficiente para su información o para que puedan ser examinadas. El Gobierno, a la mayor brevedad posible, y a reserva de una valoración definitiva, remitirá a la Cámara un sucinto informe sobre el contenido sustancial de aquellas propuestas legislativas de la Comisión Europea que tengan repercusión en España. Cuando la Comisión lo considere oportuno, podrá solicitar del Gobierno la ampliación de la información remitida. También podrá celebrar debates sobre una propuesta legislativa concreta en el seno de la Comisión y solicitar, si se considera oportuno, al Presidente de cualquiera de ambas Cámaras la celebración de un debate en el Pleno respectivo con el mismo fin, participando el Gobierno en ambos casos. Celebrado el debate regulado en el párrafo anterior, los Grupos Parlamentarios dispondrán de dos días para presentar propuestas de resolución, que serán admitidas por la Mesa de la Comisión cuando sean congruentes con la materia objeto del debate. Dichas propuestas serán sometidas a examen y votación por la Comisión, que habrá de ser convocada al efecto dentro de un plazo máximo de diez días. En este debate, las propuestas admitidas podrán ser defendidas durante un tiempo máximo de diez minutos, con posible turno en contra por el mismo tiempo.

De este modo, la modificación de la ley, en orden a ampliar las funciones del Parlamento nacional y a regular un sistema de alerta temprana con anterioridad a la entrada en vigor de la Constitución europea, podría llevarse a cabo dentro de la posibilidad que recoge el Reglamento del Parlamento Europeo de emprender negociaciones para proponer "cualesquiera otras medidas destinadas a facilitar los contactos con los Parlamentos nacionales». La modificación de la ley 8/1994 supondría por tanto ampliar el apartado b del artículo 3, regulando la posibilidad de que esta Comisión, en representación de las Cámaras, pudiera realizar un dictamen en el que se pronunciase sobre el 
correcto uso o no del principio de subsidiariedad. Dictamen que llegaría al Parlamento Europeo, tal y como se regula en el protocolo 2 del proyecto de Constitución europea. La Comisión, en este caso, tendría como fin el unificar las posturas de ambas Cámaras, en el caso de que fueran discrepantes, y siempre que ello se considerase necesario, pues también es perfectamente defendible la idea de que la actuación de cada Cámara fuese totalmente autónoma, debido a que en su composición responde a un criterio de representación diverso y diferente.

\section{b) Los frutos de los Grupos de Trabajo de la Convención Europea}

Las conclusiones establecidas en el Protocolo Anejo al Tratado de Ámsterdam, así como en la Declaración 13 aneja al Tratado de Maastricht, fueron las mismas a las que se llegaron tras los trabajos de la Convención Europea ${ }^{21}$, en concreto, los de su Grupo IV «Parlamentos nacionales", que declaró en su informe final (Informe final del grupo IV sobre el papel de los parlamentos nacionales, CONV 352/02) que hay que dar un mayor papel a los Parlamentos nacionales en los trabajos de la Unión Europea. Ya en el mismo sentido se pronunció también Giorgio Napolitano en su famoso informe, estableciendo que era necesario introducir una mayor participación de las colectividades regionales y locales en el proceso de toma de decisiones ${ }^{22}$. De este modo, los trabajos de este Grupo IV se centraron principalmente en tres aspectos:

- el papel de los Parlamentos nacionales en el control de los gobiernos;

- el papel de los Parlamentos nacionales en la supervisión de la aplicación del principio de subsidiariedad (tema que nos interesa, ya que de este control deriva la introducción del mecanismo de Alerta Temprana). Ya anteriormente, el Comité de las Regiones señaló sobre este aspecto que los principios de subsidiariedad y

21 Sobre la Convención Europea ver entre otros: BARQUERO CRUZ, J. y GIPPINI FOURNIER, E.: "La convención constitucional europea: ¿refundación o codificación?», en Actualidad Jurídica Aranzadi, n. ${ }^{\circ}$ 558, 2002; BorReLl, J., CARnero, C. y LóPEZ GARRIDO, D.: Construyendo la constitución europea. Crónica política de la Convención, Madrid, 2003.

22 Informe sobre el papel de los poderes regionales y locales en la construcción europea, conocido como el Informe Napolitano, DOC. A5-0427/2002. 
proporcionalidad deberían completarse con el fin de "garantizar las competencias de los entes regionales y locales" ${ }^{23}$;

- el papel y función de las redes o mecanismos multilaterales de participación de los Parlamentos nacionales a nivel europeo.

Durante los distintos debates se llegó a la conclusión de que era necesario ampliar el papel de los Parlamentos nacionales en el ámbito europeo, ya que en cuanto a las competencias no se plantea problema alguno con las del Parlamento Europeo, por estar estas bien diferenciadas, si bien hay otros autores que, por el contrario, manifiestan que uno de los problemas para conceder un mayor papel a los Parlamentos es precisamente que «deben competir con las funciones del Parlamento Europeo ${ }^{24}$. De este modo, se contribuiría a conseguir una mayor legitimidad democrática dentro de la Unión y lograr una Unión más próxima a los ciudadanos ${ }^{25}$.

A este respecto, se pide que quede plasmado en el texto la posición de estos Parlamentos, dejando claro que desde la Unión se quiere ampliar su papel sin interferir en ningún tipo de competencia nacional, ya que no podemos olvidar que la Unión Europea se acoge al principio de no interferencia en los ordenamientos constitucionales y territoriales ${ }^{26}$, y por esto las tentativas de los parlamentos para aumentar su nivel de participación, son de distinta fuerza o intensidad, ya que al fin y al cabo dependen del ordenamiento jurídico de los respectivos Estados miembros $^{27}$. Así, el artículo I-5 del Proyecto de Constitución Europea establece que la Unión respetará la identidad nacional de los Estados miembros en lo referente a su autonomía local y regional, y también respetará "las funciones esenciales del Estado, especialmente las que tiene por objeto garantizar su integridad territorial,...»

${ }^{23}$ Contribución del Comité de las Regiones a la Convención Europea, CdR 127/2002fin, 8.7.2002.

${ }^{24}$ GiL IBÁÑeZ, A. J.: op. cit., p. 215.

${ }^{25}$ Recordar al respecto de este tema la posición del Tribunal Constitucional Alemán que estableció que son los ciudadanos quienes, a través de sus Parlamentos nacionales, legitiman a la Unión Europea; ver BACIGALUPO, M.: "La constitucionalidad del TUE en Alemania. La Sentencia del Tribunal Constitucional Federal alemán de 12 de octubre de 1993», Gaceta Jurídica de la Comunidad Europea, Serie D, n. ${ }^{\circ} 21,1994$, p. 7 y ss.

${ }^{26}$ Pérez González, M.: «El papel de las regiones en el proceso de integración europea: aspectos institucionales", en la obra El gobierno..., op. cit., p. 281.

27 RIDEAU, J.: «El papel de los Parlamentos nacionales en la arquitectura europea", en la obra La Encrucijada constitucional de la Unión Europea, dirigida por GARcía de EnterRía, E.: Civitas, Madrid, 2002, p. 328. 
Por su parte, el Grupo, en su informe final, recomienda las siguientes medidas:

- que el futuro Tratado constitucional incluya un texto específico en el que se reconozca la importancia de que los Parlamentos nacionales participen activamente en la actividad de la Unión Europea, con la finalidad principal de que controlen la correcta aplicación del principio de subsidiariedad y proporcionalidad;

- que, siempre que se lleven a cabo funciones legislativas, el Consejo actúe en sesiones públicas;

- que los documentos del Consejo se remitan, tanto al Parlamento Europeo como a los Parlamentos nacionales en un plazo máximo de diez días.

En el informe también se establecen una serie de aspectos a tener en cuenta:

- En primer lugar, se hace alusión al hecho de que, si bien los documentos de consulta referidos anteriormente, son presentados en Internet para el conocimiento del público en general, es necesario, con la finalidad de que los Parlamentos nacionales sean más conscientes de la oportunidad que tienen de reaccionar frente a propuestas legislativas en una fase temprana del proyecto, que dichos documentos se transmitan directamente a los Parlamentos nacionales, ya que en el caso de que estos no recibieran rápidamente la información, el plazo de seis semanas que tienen para dar a conocer su opinión a los respectivos gobiernos, podría resultar insuficiente; y se plantea otro problema, siempre partiendo del hecho de que los Parlamentos nacionales no recibieran la información de manera rápida, como es el hecho de que, antes de que éstos manifiesten su opinión, los miembros del Consejo puedan comenzar a formar "acuerdos preliminares" (CONV $353 / 02$ ). Por ello siempre ha estado (Intranet) una base de datos para que los diversos órganos tuvieran acceso todos los días a los documentos y así poder agilizar y mejorar el proceso ${ }^{28}$.

- En segundo lugar, se considera también necesario que el término "propuestas legislativas» ${ }^{29}$ al que se hace referencia en el Proto-

28 GIL IBÁÑEZ, A. J.: op. cit., p. 230.

29 De esta forma la definición se refiere a los actos comunitarios (reglamentos, directivas y decisiones) contemplados en el artículo 249 TCE, así como a los actos (decisiones marco y decisiones) contempladas en el apartado 2 del artículo 34 del TUE. 
colo Anexo al Tratado de Ámsterdam, sea clarificado, se especifique aún más.

- Clarificar el contenido de las "excepciones por motivos de urgencia».

Frente a todo esto, y respecto al papel de los Parlamentos nacionales en el control de la aplicación del principio de subsidiariedad, se plantean una serie de interrogantes. ¿Qué función tienen los Parlamentos nacionales? ¿Deben actuar solos o con otros órganos? ¿En qué fase del proceso legislativo deben participar? ¿Qué mecanismo es el más adecuado? que:

Sobre todas estas cuestiones, el Grupo llegó a la conclusión de

- El momento de participación debería ser tan pronto como fuera posible, dentro del proceso; en concreto, el Grupo I, en sus Conclusiones (CONV 286/02), estableció que la participación en el proceso legislativo debería llevarse a cabo durante la fase de elaboración de la propuesta del acto legislativo;

- Que el control sería de carácter político;

- Que no es necesaria la creación de nuevos órganos para ello, sino que pueden actuar solos, opción igualmente apoyada por el Grupo I, Subsidiariedad (CONV 286/02).

Como se ha establecido anteriormente, fruto de los trabajos de la Convención se redactó y firmó el texto del Proyecto de Constitución Europea, y una serie de protocolos y declaraciones anejas, entre las que destacamos por su directa relación con el tema analizado, el protocolo 1 y 2.

En el protocolo 1, sobre la función de los Parlamentos nacionales en la Unión Europea, se hace referencia principalmente al deber de informar a los Parlamentos nacionales, pero no se introducen un número significativo de novedades con respecto al Protocolo de Ámsterdam. Así se establece:

- que la Comisión debe trasmitir a los Parlamentos nacionales, una vez que se hayan publicado, todos los documentos de consulta, entendiendo por tales los libros blancos, los libros verdes y las comunicaciones;

- que también se les hará llegar, al mismo tiempo que al Parlamento Europeo y al Consejo, el programa legislativo anual o cual- 
quier otro instrumento de programación legislativa o de estrategia política (Así se establece en el Protocolo I, Adenda I al documento CIG 87/04 REV 1);

- establece el hecho de que los Parlamentos nacionales también conocerán de las propuestas de actos legislativos y podrán dirigir un dictamen motivado, según el procedimiento establecido en el Protocolo II, sobre la adecuación del principio de subsidiariedad con la propuesta. Para ello diferencia entre propuestas de actos legislativos que tienen su origen en la Comisión, Parlamentos Europeo, grupo de estados miembros, Tribunal de justicia, Banco Central Europeo y Banco Europeo de Inversiones

Respecto al plazo de tiempo, reseñar que entre el momento en que se trasmite a los Parlamentos nacionales un proyecto de acto legislativo, y la fecha de inclusión del mismo en el orden del día provisional del Consejo, debe transcurrir un plazo de seis semanas (salvo las excepciones por motivos de urgencia).

El Protocolo también regula el hecho de que los órdenes del día y los resultados de las sesiones del Consejo se trasmitirán directamente a los Parlamentos nacionales y a los gobiernos de los Estados miembros.

Importante también es el artículo 8 del Protocolo que establece que cuando el sistema parlamentario nacional no sea monocameral, las disposiciones anteriores se aplicarán a las cámaras que lo compongan.

En el título II del protocolo se hace referencia a la cooperación interparlamentaria entre el Parlamento Europeo y los Parlamentos nacionales, con el fin de lograr un funcionamiento de la Unión europea más eficaz y regular. En este sentido, y a diferencia del mecanismo de alerta temprana, la participación aquí de los Parlamentos nacionales es indirecta (no olvidemos que la participación directa de los parlamentos nacionales se limita a casos excepcionales ${ }^{30}$ ), pero importante, ya que el hecho de que se les tengan que transmitir estos documentos tiene como finalidad principal el que puedan llevar a cabo de forma correcta sus funciones de seguimiento, de control de la actividad de sus respectivos gobiernos en los asuntos comunitarios, etc. ${ }^{31}$.

30 ZEMÁNEK, J.: "Improving the Union's legitimacy: the European Parliament and National Parliaments", en la obra El gobierno de..., op. cit., p. 240.

31 Delgado-Iribarren García-Campero, M.: op. cit.; p. 765. 
En el protocolo 2 se desarrolla el procedimiento de Alerta temprana al que hace referencia el artículo 3 del Protocolo 1, mecanismo que deben seguir los Parlamentos nacionales para llevar a acabo control de la aplicación del principio de subsidiariedad, y mecanismo cuya implantación ya propuso el Grupo I, Subsidiariedad, en la Convención Europea, en su Informe de Conclusiones, señalando la necesidad de llevar a cabo un control político previo, denominado "de alerta rápida" (early warning sistem, CONV 286/02).

\section{EL MECANISMO DE ALERTA TEMPRANA}

Fue el Grupo I de trabajo de la Convención Europea quien solicitó la creación de dicho mecanismo, estableciendo que el Tratado debería recoger, en cuanto a su contenido, lo siguiente (CONV 286/02):

- Que las propuestas de carácter legislativo elaboradas por la Comisión se harían llegar en el mismo plazo de tiempo, tanto al Parlamento Europeo y al Consejo, como a cada Parlamento nacional, entiendo por tal cada una de las Cámaras del mismo.

- Que los Parlamentos nacionales tendrán un plazo de seis semanas, desde que reciben las propuestas, para realizar, si lo estiman conveniente, un dictamen motivado y claro, respaldado por una mayoría, sobre el uso, correcto o no, realizado del principio de subsidiariedad, dictamen que será enviado al presidente del Consejo, de la Comisión y del Parlamento Europeo.

De este modo el sistema de la alerta temprana es una novedad introducida por el Grupo de trabajo I de la Convención, grupo dirigido por el eurodiputado español, Iñigo Méndez de Vigo, consiguiendo de esta forma rechazar la propuesta de crear un órgano nuevo ad hoc. Y es que previamente algunos miembros del Grupo propusieron en los debates la creación de un órgano nuevo para llevar a cabo las funciones que implicase el nuevo sistema, propuesta que finalmente no vio la luz, y que en caso contrario hubiera supuesto una serie de problemas añadidos al ya difícil proceso decisorio, en cuanto hubiera supuesto un aumento en la actual carga burocrática ${ }^{32}$. Se trata de un mecanismo cuya finalidad es que los Parlamentos nacionales, una vez conocidas las propuestas de actos legislativos de la Comisión Europea, se pronuncien

${ }^{32}$ Convención Europea. Secretaría. Bruselas, 30 de julio de 2002. CONV 210/02. WGI 9 y WGIV 8. 
mediante un dictamen motivado, sobre el correcto uso en dicha propuesta del principio de subsidiariedad ${ }^{33}$.

De los trabajos del Grupo I de la Convención, al que también se acabó uniendo el Grupo IV, deriva el Protocolo 2 anejo al Tratado por el que se establece una Constitución para Europa, y en el que se recoge, derivado de lo establecido en los protocolos anejos de los anteriores Tratados (Ámsterdam y Maastricht), el interés en aumentar el papel de los Parlamentos nacionales en el ámbito comunitario, y el sistema de alerta temprana. Se trata en definitiva, de un control de carácter previo que llevarán a cabo los Parlamentos nacionales, sobre la correcta aplicación del principio de subsidiariedad, y cuya naturaleza, jurídica o política, estará en función del proyecto que se presente.

Continuando con lo anterior, se presentan una serie de cuestiones: ¿qué propuestas pueden ser objeto de este sistema?, ¿cuál es el tiempo y la forma de realizarlo?, etc. Derivado del hecho de que todas las instituciones de la Unión han de velar por el respeto al principio de subsidiariedad, y también de que antes de proponer un acto legislativo la Comisión ha de llevar a cabo diversas consultas, en orden a no dejar de lado, cuando proceda, la dimensión regional y local de sus propuestas (Así se recoge en los artículos 1 y 2 del Protocolo sobre la aplicación de los principios de subsidiariedad y proporcionalidad), se establece en el artículo 4 del Protocolo sobre subsidiariedad, que serán los «proyectos de actos legislativos europeos", los que, tanto la Comisión como el Parlamento Europeo y el Consejo (en los casos establecidos en el párrafo $3)$, han de transmitir a los Parlamentos nacionales. Según el artículo 3 del citado protocolo, se entenderá por acto legislativo europeo: "las propuestas de la Comisión, las iniciativas de un grupo de Estados miembros, las iniciativas del Parlamento Europeo, las peticiones del Tribunal de Justicia, las recomendaciones del Banco Central Europeo, y las peticiones del Banco Europeo de Inversiones, destinadas a la adopción de un acto legislativo europeo" (definición que se repite en los mismos términos en el artículo 2, apartado 2 del Protocolo 1). De esta forma sólo podemos incluir las leyes europeas y leyes marco europeas, quedando excluidos el Reglamento europeo, la Decisión europea, las Recomendaciones y los Dictámenes, por no serlo (Artículos I-33 a I-35 del Proyecto de Constitución europea), y quedando también excluidas aquellas materias que no puedan ser reguladas por actos legislativos

33 BermanN, G.: "Taking Subsidiarity Seriously: Federalism in the European Community and the United status", en Comparative Constitutional Law, Jaccson \& Tushnet (ed), Foundation Press, Nueva York, 1999, pag.. 882. 
(Por ejemplo el ámbito de la política exterior y seguridad común, que según el artículo l-40.7 será regulada por decisión europea del Consejo).

Otro punto a tener en cuenta es el hecho de que en el artículo 4 del Protocolo se establece que se trasmitirán tanto los proyectos de actos legislativos europeos, como sus "proyectos modificados". Esto nos da a entender que podemos encontrarnos ante el hecho de que los Parlamentos nacionales puedan contar con dos momentos, dentro del procedimiento legislativo para hacer uso del mecanismo de alerta temprana: durante el comienzo del procedimiento, y en un momento más avanzado en el caso de que se hubiese producido alguna modificación. Sin embargo, tras los debates de los Grupos I y IV de la Convención (CONV 286/02 y 630/03), se concluyó que, salvo casos excepcionales, el mecanismo de alerta temprana sólo se podrá aplicar al inicio del procedimiento por varios motivos, como el hecho de que las modificaciones posteriores en el acto no tienen por qué afectar a la aplicación del principio de subsidiariedad, que es en definitiva sobre lo que se pronuncian los Parlamentos nacionales. A esto también habría que añadir la enorme dificultad que entrañaría reanudar este mecanismo en un momento posterior al procedimiento ${ }^{34}$.

Los proyectos de actos legislativos que se dan a conocer a los Parlamentos nacionales, y que son elaborados por la Comisión, o, en los casos que corresponda, por el Tribunal de Justicia, el Banco Central Europeo y el Banco Europeo de Inversiones, se encontrarán motivados en relación con los principios de subsidiariedad y proporcionalidad, para permitir de este modo a los Parlamentos nacionales pronunciarse sobre dichos principios. Con ese fin, se establece que han de incluir una ficha (Artículo 5 del Protocolo) con los pormenores que permitan evaluar dicho cumplimiento. En concreto ha de contener:

- los elementos que permitan evaluar el impacto financiero, es decir, cualquier tipo de efecto económico que pudiera derivarse de la propuesta;

- los efectos que han de desarrollar los Estados miembros en sus respectivas normativas, incluida, cuando proceda, la legislación regional, en el caso de que la propuesta de acto legislativo se refiera a una ley marco europea;

- las razones que justifiquen la conclusión de que un objetivo de la Unión puede alcanzarse mejor en el plano de ésta, lo cual se dará

34 Delgado-Iribarren García-Campero, M.: op. cit.; p. 783. 
a conocer mediante indicadores cualitativos y, cuando sea posible, cuantitativos;

- el principio de proporcionalidad, ya que se establece que los proyectos de actos legislativos tendrán en cuenta el hecho de que cualquier carga ${ }^{35}$ que pueda presentarse, tanto administrativa como financiera, ha de ser lo más reducida posible y proporcional al objetivo que se desea alcanzar.

Todo Parlamento nacional o toda Cámara de uno de estos parlamentos, en el caso de que éste sea bicameral, posee un plazo de seis semanas, a partir de la fecha de transmisión de un proyecto de acto legislativo europeo, para dirigir a los presidentes del Parlamento Europeo, Consejo y Comisión un dictamen motivado que exponga las razones por las que se considera que el proyecto no se ajusta al principio de subsidiariedad, tal y como se establece en el artículo 6 del Protocolo de subsidiariedad. Para llevar a cabo esta función, cada Parlamento nacional dispone de dos votos, que repartirán en función de su sistema parlamentario, ya que en caso de que sea bicameral, cada cámara dispondrá de un voto, pudiendo manifestarse cada una de ellas de modo distintito debido a que en los Estados con sistema bicameral la segunda cámara puede representar intereses diferentes de la primera o estar compuesta por mayorías políticas distintas.

De lo anteriormente expuesto se deriva el hecho de que son los Parlamentos nacionales quienes poseen dicha potestad, considerados en su conjunto, en cuyo caso le corresponden dos votos, o por separado, teniendo un voto por cámara, y con el fin de mantener una igualdad entre los Estados miembros, es decir, que no haya diferencias con base en el sistema parlamentario que ostenten, que no se penalice a los Estados miembros cuyos parlamentos no tienen más que una cámara (CONV 630/03).

El artículo 6 del Protocolo 2 establece que, además de al Presidente del Parlamento Europeo, Consejo, Comisión, dicho dictamen deberá ser transmitido a los Gobiernos de los Estados miembros en el caso de que el proyecto de acto legislativo tuviera su origen en un grupo de ellos; o a la institución correspondiente si dicho proyecto proviene del Tribunal de Justicia, Banco Central Europeo o banco Europeo de Inversiones.

35 El artículo 5 del Protocolo establece que por carga debemos entender aquellas que puedan recaer sobre "la Unión, los gobiernos nacionales, las autoridades regionales o locales, los agentes económicos o los ciudadanos". 
El objeto del dictamen elaborado por los Parlamentos nacionales es el comprobar el correcto uso del principio de subsidiariedad. Por tanto, los parlamentos sólo emitirán dictámenes en el caso en el que consideren que en el proyecto de acto legislativo no se respeta dicho principio. Se trata por tanto de un mero control previo. En el supuesto de que el Parlamento nacional no emitiese un dictamen, se entiende que han considerado como correcto el uso del principio de subsidiariedad en el proyecto de acto legislativo que previamente han analizado.

Con respecto a los aspectos formales, el artículo 6 del Protocolo establece únicamente que el dictamen ha de ser motivado, es decir, que exponga las razones por las que se considera que el principio de subsidiariedad no se ha usado de modo correcto, es decir, justificándolo en el hecho de que, para ese caso particular, no es necesario que la Unión Europea intervenga para la regulación de dicha materia, ya que puede llevarse a cabo de manera correcta por los Estados miembros.

Se establece que ha de emitirse en una de las lenguas oficiales de la Unión, pero no se añade ningún otro requisito, por lo que podemos decir que se deja amplia libertad formal, lo que conlleva que los Parlamentos nacionales establezcan algún procedimiento que permita buscar una posición común o cómo actuar separadamente. Esto es lógico si partimos del hecho de que no existe un modelo único ni siquiera para el procedimiento legislativo, en el sentido de número de lecturas que recibe un texto legislativo en la Cámara ${ }^{36}$.

A la hora de determinar el procedimiento parlamentario para la aprobación del dictamen, las soluciones pueden ser varias. Dada la brevedad de los plazos, de seis semanas, o bien se acude al procedimiento de lectura única, con los inconvenientes que presenta para las minorías, o bien se establece un procedimiento ad hoc, posiblemente la opción mas adecuada, que tenga en cuenta la posición de aquellas y su necesaria compatibilidad con la preclusividad de los plazos. En todo caso, y en función de la complejidad técnica del dictamen, podría preverse la comparecencia urgente de expertos en la materia, o la emisión por parte de éstos, junto los servicios jurídicos de la Cámara, de informes por escrito.

Con respecto al contenido del dictamen, será motivado, es decir, ha de expresar claramente los motivos por los que se considera que no se ha usado correctamente el principio de subsidiariedad. Debido a que su

36 García-Escudero Márouez, P.: «El procedimiento legislativo en las Cortes Generales: notas y bases para una reforma", REDC, n. ${ }^{\circ} 74$, mayo-agosto 2005, p. 227. 
función última es convencer a las autoridades correspondientes de ese uso incorrecto del principio, la lógica nos invita a pensar que no debería tratarse de un dictamen largo, sino claro, sistemático y con rigor, donde las decisiones se adoptasen por mayoría, pero, en cualquier caso con la presencia de los votos particulares, pues su existencia coadyuva a formar la voluntad del órgano receptor, procedentes de las minorías.

Frente a toda esta imprecisión de aspectos formales susceptibles de ser regulados en los Reglamentos de las Cámaras, el Protocolo 2 establece un plazo para realizar dicho dictamen, de seis semanas, pero no desde que los Parlamentos nacionales reciben el proyecto, sino que el plazo comienza a computar desde la fecha de transmisión de la propuesta legislativa (art. 4 del Protocolo I). Serán los presidentes de los Parlamentos nacionales, quienes han de enviar al presidente de las respectivas instituciones dicho dictamen.

Ciertamente, se trata de un plazo muy breve ya que en seis semanas se deben enviar los informes, recibirlos en los distintos Parlamentos nacionales, elaborar los dictámenes y de nuevo reenviarlas al presidente de la respectiva institución para su inclusión en el orden del día provisional. Sin duda alguna, los Parlamentos nacionales y regionales se encuentran ante un supuesto donde deben poner a prueba todas sus capacidades para estar a la altura de las circunstancias en su condición de instancias representativas y tratar de ofrecer una solución a los problemas planteados.

\section{CONSECUENCIAS DE LA ALERTA TEMPRANA}

En un principio, las conclusiones del Grupo I, Subsidiariedad, sobre este aspecto, fueron las siguientes (CONV 286/02): se estableció que la decisión final habría de depender de la cantidad y contenido de los dictámenes recibidos, estableciendo que, si el número de dictámenes recibidos fuera mínimo, la Comisión se limitaría simplemente a motivar con mayor detalle el acto respecto de la subsidiariedad, y en el caso en el que el número de dictámenes recibidos superase al tercio del número de Parlamentos nacionales, la Comisión revisaría su propuesta, pero sin tener la obligación de retirarla ni modificarla.

Con el Protocolo de Subsidiariedad, el asunto se clarifica aún mucho más, y así en su artículo 7 se establece que las instituciones de la Unión, anteriormente citadas, de las que pueden provenir proyectos de actos legislativos, "tendrán en cuenta" los dictámenes motivados que 
les han dirigido los Parlamentos nacionales o cualquiera de sus cámaras.

Por tanto partimos del hecho de que si una cámara estima que el proyecto de acto legislativo no respeta el principio de subsidiariedad, emitirá un dictamen motivado, es decir, un voto negativo. En el caso de que el número de votos llegue a un determinado umbral, ese "tener en cuenta" se convierte en un "deber de volver a estudiar el proyecto" (artículo 7 del Protocolo 2). Este deber de reexamen se producirá en dos casos:

- Cuando los dictámenes que se hayan emitido representen, al menos, un tercio del total de los votos atribuidos a los Parlamentos nacionales. Siendo 25 los Estados miembros, dicha cifra se sitúa en 17 votos. Es decir, cuando la Comisión reciba 17 votos negativos a su propuesta deberá proceder a nuevo examen de la misma.

- Cuando, siendo el proyecto de acto legislativo referente al espacio de libertad, seguridad y justicia, del artículo III-264 del Proyecto de Constitución Europea, los dictámenes emitidos representasen al menos la cuarta parte de los votos, es decir, 13 votos.

El hecho de que la institución correspondiente de la que emanó el proyecto de acto, (Comisión, Parlamento Europeo, Tribunal de Justicia, Banco Central Europeo, Banco Europeo de Inversiones) o en su caso, el grupo de Estados miembros, deba volver a estudiar el proyecto no implica nada más que eso, ya que tras este nuevo estudio, la institución correspondiente podrá decidir entre mantener el proyecto, modificarlo o retirarlo, siempre motivando su decisión, sin tener la obligación de realizar ninguno de los anteriores actos en concreto (artículo 8 del Protocolo). Por tanto el hecho de que el proyecto de acto legislativo recibiera los 17 o 13 votos exigidos, según el caso, únicamente conllevaría una interrupción del procedimiento para el reexamen de la propuesta, y la posterior emisión por la institución correspondiente de un informe sobre la decisión tomada: mantener, modificar o retirar la propuesta.

Llegados a este punto, parece obvia la existencia de una serie de lagunas al respecto. Ante la cuestión ¿qué debe realizar la Comisión si el número de dictámenes recibidos en contra de la propuesta, no sólo llegase al mínimo exigido, sino que lo superase con creces? Parece lógico pensar que en estos casos la Comisión no debería continuar adelante con esa propuesta. Durante los trabajos de la Convención y tal y como se reconoce en el documento CONV 630/03, se trató la posibilidad de 
instaurar un mecanismo de "tarjeta roja" o de veto para aquellos casos en el que se traspasase el umbral de los dos tercios, pero dicho sistema tuvo una fuerte oposición y finalmente no fue adoptado.

En definitiva, se trata de un sistema cuya finalidad principal no es solamente que los Parlamentos nacionales estén informados acerca de los asuntos europeos, sino que pueden de algún modo influir con sus opiniones y criterios $^{37}$.

\section{OTROS TIPOS DE CONTROL DE LOS PARLAMENTOS NACIONALES: CONTROL A POSTERIORI}

El Grupo I alude a la posibilidad de introducir un control a posterio$\mathrm{ri}^{38}$ consistente en la creación de un recurso por violación del principio de subsidiariedad, reforzando de este modo el control que, respecto a este principio, lleva a cabo el Tribunal de Justicia, y permitiendo que sean los Parlamentos nacionales quienes recurran. Como límite se propone que sólo se llegue a él en supuestos límite y excepcionales, como pudiera ser un caso en el que políticamente no se hubiera podido alcanzar una decisión. Como se establece en el informe resumido de la sesión plenaria, celebrada los días 17 y 18 de marzo de 2003, en Bruselas con motivo de la Convención Europea, muchos convencionalistas insistieron también en el hecho de que las regiones con competencias legislativas pudieran también, directa o indirectamente, recurrir al Tribunal de Justicia (CONV 630/03).

Con la creación del protocolo sobre la aplicación de los principios de subsidiariedad y proporcionalidad, aparecen como novedades fundamentales no sólo la creación de un nuevo mecanismo, denominado "alerta temprana", sino que también queda plasmado lo que en la Convención se venía acordando, es decir, la posibilidad de que los Parlamentos nacionales puedan recurrir ante el Tribunal de Justicia ${ }^{39}$, si bien se especifica que la legitimación procesal no la tienen directamente las Cámaras, como en principio pretendía el grupo de Trabajo I, sino los gobiernos, en nombre de su Parlamento o de una cámara del mismo. Por lo tanto, siempre que la Cámara se lo requiera, el gobierno

37 Delgado-Iribarren García-Campero, M.: "La función de los Parlamentos nacionales en la arquitectura europea", en la obra La Encrucijada..., op. cit., p. 393.

38 Opción también propuesta por Giorgio Napolitano en su informe. Informe sobre el papel de los poderes regionales y locales en la construcción europea, DOC. A5-0427/2002.

39 Prieto Gutiérrez, M. G.: op. cit, p. 818. 
deberá plantear el recurso ante el Tribunal de Justicia ${ }^{40}$. Se trata de este modo de la creación de un "control de naturaleza judicial»" ${ }^{41}$, a diferencia del sistema de alerta temprana (control de naturaleza política y previa).

En relación con este control judicial se plantea la cuestión de si es obligatorio para el Gobierno presentar dicho recurso cuando lo requiera la cámara. Realmente el artículo 7 del Protocolo hace referencia a que el Tribunal de Justicia será competente, pero nada establece acerca de la obligación del Gobierno. Simplemente remite a que se realice conforme al procedimiento del artículo III-365 del Proyecto de Constitución. Si tenemos en cuenta que durante la Convención se quería atribuir legitimación procesal directa a la Cámaras, podemos interpretarlo como que efectivamente, el gobierno está obligado a ello y para esto basta con que se lo requiera una de las cámaras. Pero también podemos establecer que existe una laguna al respecto, ya que no se establece de manera clara ni en el artículo 7 del Protocolo ni en el III365 . El tema debe ser objeto de una regulación normativa, tanto en el Derecho comunitario como en el Derecho interno, cabiendo las siguientes posibilidades:

- Que se regule en los respectivos Reglamentos de las Cámaras. En base a unos criterios uniformes, ya que en otro caso carecería de sentido, y evitando cualquier tipo de vulneración del principio de reserva de ley.

- Que venga legalmente establecido en la ley que regula la composición y funciones de la Comisión mixta creada al respecto, o en la propia Ley del Gobierno.

- Que la regulación normativa se efectué en la normativa interna del Tribunal de Justicia.

Incluso podemos añadir que, independientemente del modo en que se lleve a cabo, también debe regularse que cuando dicha solicitud

40 El Artículo 8 del Protocolo de subsidiariedad señala expresamente: «El Tribunal de Justicia de la Unión Europea será competente para pronunciarse sobre los recursos por violación del principio de subsidiariedad, por parte de un acto legislativo europeo, interpuesto con arreglo a los procedimientos establecidos en el artículo III-365 de la Constitución, por un Estado miembro, o transmitidos por éste de conformidad con su ordenamiento jurídico en nombre de su parlamento nacional o de una cámara del mismo.»

41 Mangas Martín, A.: op. cit., p.139. 
provenga de los Parlamentos nacionales, ha de tener un carácter vinculante.

Pese a que en el Protocolo sólo se establece la posibilidad de que sean los Parlamentos nacionales quienes puedan solicitar dicho recurso, considero que se trata de una opción que también debería brindarse a los Parlamentos regionales. Pero no en el caso de que solamente uno de ellos así lo considerase oportuno, sino que exigiéndose que lo demandase un determinado número de ellos. Por ejemplo sería correcto exigir que al menos un tercio, o la mitad, de los Parlamentos regionales manifestasen la necesidad de solicitar dicho control a posteriori, el cual también debería tener un carácter vinculante.

En cualquier caso, el protocolo también establece en su artículo 9 que la Comisión presentará al Consejo Europeo, al Parlamento Europeo, al Consejo y a los Parlamentos Nacionales un informe anual sobre la aplicación del artículo I-11 del Proyecto de Constitución Europea, donde entre otros se contiene el principio de subsidiariedad. Dicho principio, no debemos olvidarlo, consiste en asegurar que el nivel superior, en este caso la Unión Europea, sólo actúe cuando se demuestre que con su acción, los resultados que se pretenden alcanzar serán más eficaces que en el caso en que dicha acción sea llevada a cabo por los niveles inferiores, es decir, en este caso los Estados miembros. Se trata por lo tanto de una manifestación del principio de subsidiariedad en su fase ascendente. Pero no podemos dejar de lado el hecho de que este principio tiene otra manifestación. En su sentido descendente este principio conlleva la protección de los Estados miembros, de los entes regionales y locales en aquellos casos en los que los gobiernos de nivel superior, en base a las competencias comunitarias, pretendan llevar a cabo actos basándose en competencias que no les pertenecen.

\section{EL PAPEL DE LOS PARLAMENTOS REGIONALES}

El principio de autonomía institucional tradicionalmente sostenido por el TJCE ha implicado la ceguera de la Comunidad frente a la estructura interna de los Estados miembros. Sin embargo las consecuencias serán distintas según se aplique a la fase ascendente (proceso de elaboración) o descendente (aplicación y ejecución). Con respecto a esta última no parece existir problema teórico alguno: será aplicado por quienes tengan reconocido las competencias en la instancia interna. Otra cuestión son los problemas derivados de la presunta «invasión competencial", mediante la utilización de títulos horizontales, por parte de los Estados miembros en relación con la aplicación del Derecho 
comunitario. Por lo que se refiere a la fase ascendente, son los gobiernos centrales quienes, como miembros del Consejo, ganan competencias o capacidad de intervención. La compensación de estos efectos debe llevarse a cabo por los propios Estados y mediante su vía interna, mediante mecanismos internos de participación, etc. que posibiliten la intervención de las regiones. A tal efecto, algunos países han adoptado ya determinadas soluciones:

- Alemania modificó su Ley Fundamental en 1992 para permitir la participación de los Länder en los asuntos europeos mediante el Bundesrat.

- Italia reformó la constitución en octubre de 2001 para introducir el principio e participación regional en los asuntos europeos (Art. 177).

- En España no se encuentra recogido en ningún precepto constitucional, debiendo ser, a nuestro juicio, una de las cuestiones a debatir en el actual proceso de reforma constitucional.

$Y$ es que, a estas alturas, parece resultar obvio el afirmar que las entidades políticamente descentralizadas han perdido mayor número de competencias que los Estados miembros en el proceso de integración europea. Por ello:

- Las regiones no solo deben participar en la fase descendente del derecho comunitario, es decir, en su ejecución y aplicación, sino que debería reconocérsele un derecho a intervenir en el plano ascendente, es decir, en la elaboración del mismo;

- No solo los Parlamentos nacionales, sino también los regionales debieran participar, convirtiéndose en actores protagonistas de la gestación de normas comunitarias, sin olvidar el respeto al principio de unidad de acción exterior.

El tema de la participación de los Parlamentos nacionales en la Unión Europea ha pasado en los últimos años a ocupar un papel privilegiado dentro del debate sobre el futuro de la Unión, debido entre otras causas al hecho de que éstos han manifestado su interés por aumentar su participación en la Unión. El papel de estos Parlamentos se venía plasmando en las Constituciones de sus respectivos Estados miembros, si bien en algunas (España, Grecia, Italia, Irlanda, Países Bajos) no se hacía mención alguna a este hecho ${ }^{42}$. Pero hasta el mo-

42 RIDEAU, J.: op. cit., p. 342. 
mento, la participación de las CCAA se limita al Acuerdo de la Conferencia para Asuntos relacionados con las Comunidades Europeas de 1994, que únicamente recoge la realización de conferencias sectoriales, como órganos de encuentro y cooperación entre el Estado y las Comunidades Autónomas. Aún en este caso, se trata de un modelo que plantea problemas. A ellos hay que añadir los recientes Acuerdos adoptados el 9 de diciembre de 2004, donde, dando un paso hacia delante, se prevé la participación, a través de la presencia de un consejero autonómico formando parte de la delegación estatal, de las CCAA en el Consejo en temas como el empleo, la política social, sanidad y consumo, agricultura y pesca, medio ambiente, educación, juventud y cultura. Por otra parte, la cuestión regional, a pesar de no contar con ningún grupo de trabajo en la Convención fue ampliamente debatida en el seno del proceso convencional.

Consecuencia de lo anterior, se plantea también el debate sobre la participación de los Parlamentos regionales. Aunque el debate sobre el reconocimiento de las regiones en la Unión Europea es ya antiguo, las opiniones vertidas al respecto continúan siendo numerosas, y la cuestión está lejos de haber quedado definitivamente solventada. Recordemos, para dar una idea del largo recorrido de la polémica, que los primeros pasos hacia la participación de las regiones en el sistema institucional comunitario se dieron en el marco de la política regional. Esta política comunitaria se inició en los años sesenta y, tras la primera ampliación de las Comunidades, se creo en 1975 el Fondo Europeo de Desarrollo Regional (FEDER) y el Comité de Política Regional, como órgano consultivo de la Comisión. En esta primera etapa, sin embargo, no se va a reconocer ningún papel a las regiones. La reglamentación comunitaria sobre fondos estructurales adoptada en 1988 someterá las intervenciones de dichos fondos, entre ellos el FEDER, a varios principios, de los cuales interesa resaltar el principio de cooperación (o "partenariado"). Conforme al mismo, la preparación, financiación, seguimiento y evaluación de las intervenciones debía realizarse en estrecha cooperación entre la Comisión, el Estado miembro interesado y las autoridades competentes designadas por el mismo a escala nacional, regional o local. De esta forma, las regiones hacen su aparición en la elaboración de los Planes de Desarrollo, en la definición de los Marcos Comunitarios de Apoyo, en los Programas Operativos y en los Comités de Seguimiento creados por cada programa. La reforma de 1988 daría lugar, por otra parte, a la sustitución del Comité de Política Regional por el Comité para el Desarrollo y la Reconversión de las Regiones, de composición y funciones similares al anterior, si bien algunos Estados miembros (Alemania y Bélgica) incluirían en sus delegaciones a re- 
presentantes regionales. No obstante, unos meses antes de entrara en vigor dicha reforma y al calor del principio de "partenariado", la Comisión creó el Consejo Consultivo de Entes Locales y Regionales. Este Consejo nacía como un órgano adscrito a los servicios de la Comisión (a la entonces DG XVI) al que estos solicitarían dictámenes consultivos en relación con la política regional y, en general, sobre las implicaciones regionales y locales de cualquier política comunitaria.

La creación del Consejo Consultivo tuvo, sin duda, una gran relevancia para las regiones, pero resultaba a todas luces insuficiente teniendo en cuenta, en particular, la creciente incidencia de las políticas comunitarias -no sólo de la política regional- en la esfera de competencias e intereses de aquéllas. En este sentido se manifestaría la Asamblea de Regiones de Europa (ARE), en una resolución aprobada el 6 de diciembre de 1990, dirigida al Consejo Europeo que iba a celebrarse en Roma los días 14 y 15 del mismo mes, y en el que se acordaría la convocatoria de Conferencias Intergubernamentales que desembocaron en la cumbre de Maastricht. En dicha resolución, la ARE solicitaba, en consecuencia, la creación, en una primera etapa, de un órgano independiente de representación de las regiones que participase en el proceso decisorio comunitario con funciones consultivas $y$, a medio plazo, la institución de una Cámara Regional. A pesar de las reticencias de algunos Estados miembros, el Consejo Europeo de Roma de 1990 (Roma I) acordó que la Conferencia Intergubernamental sobre Unión Política tomase en consideración los intereses particulares de las regiones con vistas a reforzar la legitimidad democrática.

Iniciada la Conferencia Intergubernamental para la Unión Política a finales de 1990, los Estados miembros debaten entre dos posibilidades. Algunos (Alemania, España) defienden la necesidad de dotar a la Comunidad Europea de un órgano regional independiente, iniciativa que recibe el apoyo de la Comisión y del Parlamento europeo. Otros Estados, en cambio, se decantan por la creación de un Comité Regional en el seno del Comité Económico y Social, como "mal menor" y ante la necesidad de dar alguna satisfacción a los primeros. La primera opción fue finalmente acogida por el Tratado de la Unión Europea, siguiendo los términos de la propuesta que presento la Comisión. Nacía así el Comité de las Regiones, como un órgano separado del Comité Económico y Social (CES), aunque inspirado en el modelo de éste y con el que compartiría, en una primera etapa, una estructura organizativa común.

Pero conviene a este respecto destacar el papel de los Parlamentos regionales en el Parlamento Europeo. Como se ha establecido a lo largo de este estudio, al igual que para los Estados miembros, los distin- 
tos cauces en orden a la participación de los Parlamentos se han ido abriendo muy poco a poco. Previos al Tratado de Maastricht nos encontramos con distintas vías de participación en los procesos decisorios como la participación en diversos órganos consultivos en el marco de la política regional, actuaciones de diversas asociaciones interregionales europeas, etc. De este modo las regiones habían conseguido antes de Maastricht discretos resultados, con distinto éxito debido a la diversidad en la estructura territorial y política de los Estados miembros, y en consecuencia de la distinta disposición de estos a aceptar o no una presencia regional en el proceso de integración.

El Dictamen del Comité de las Regiones, de 14 de noviembre de 2001, sobre la participación de los representantes de los gobiernos regionales en los trabajos del Consejo de la Unión Europea, afirmaba que "el derecho de participación de las autoridades locales y regionales en la definición de las políticas de decisión de la Unión Europea, contribuye a lograr el objetivo fundamental del artículo 1 del Tratado, según el cual 'las decisiones serán tomadas de la forma más abierta y próxima a los ciudadanos que sea posible', y está al servicio del objetivo del principio de subsidiariedad según se establece en el artículo 5 del Tratado CE que estipula que en los ámbitos que no sean de su competencia, la Comunidad intervendrá solo en la medida en que los objetivos de la acción pretendida no puedan ser alcanzados de manera suficiente a nivel nacional, y regional o local». De este modo, éstos han visto aumentado su papel comenzando por el desarrollo de una política regional, para pasar después a la creación del Comité de las Regiones y, posteriormente, ir aumentando paulatinamente sus competencias.

El actual proyecto de Constitución Europea recoge en el apartado segundo del artículo 5 del Protocolo de subsidiariedad que «Incumbirá a cada Parlamento nacional o a cada cámara de un parlamento nacional consultar, cuando proceda, a los parlamentos regionales que posean competencias legislativas». De esta forma se presenta una novedad: la posible participación de los Parlamentos regionales en el mecanismo de alerta temprana ${ }^{43}$. Ya anteriormente, algunos convencionalistas, sobre todo observadores miembros del Comité de las Regiones, deseaban que se ampliasen las funciones del Comité en materia de control de subsidiaridad y que se equiparasen a la de los Parlamentos nacio-

43 Véase entre la bibliografía reciente: SANTALÓ I BURRULL: "Parlamentos regionales y Unión Europea», en Parlamentos y Regiones en la construcción de Europa, IX Jornadas de la Asociación española de Letrados de Parlamentos, AELPA y Tecnos, Madrid, 2003, p. 175 y ss; ALDECOA LuZZÚRRAGA: "Las relaciones exteriores de las Regiones", en Parlamentos y..., op. cit., p. 225 y SS. 
nales (CONV 630/03). Por tanto, además, cada cámara de un Parlamento nacional, consultará, cuando proceda, a los parlamentos regionales que posean competencias legislativas. De este hecho se derivan varios puntos a tener en cuenta ${ }^{44}$ :

- Por un lado el hecho de que se trata de una mera posibilidad, es decir, en cualquier caso el Protocolo no obliga a realizar esa consulta, ni, en el caso de que se llevase a cabo, se obliga a seguir los criterios establecidos por los Parlamentos regionales. La previsión que se contiene sobre el mecanismo de alerta temprana es la posibilidad de que las regiones intervengan, pero es una previsión que carece de valor habilitante.

- Descartada la remisión directa de los dictámenes al órgano comunitario transmisor, lo lógico sería que el mismo fuese enviado a la Cámara territorial, en nuestro caso al Senado, el cual podría asumirlo como propio, o bien incluirlo junto al suyo y remitirlo al órgano comunitario competente.

- Consecuente con lo anterior, el llevar a cabo esta consulta tendría consecuencias positivas, como el hecho de que el dictamen del Senado vendría también respaldado por la opinión de los Parlamentos regionales. Es decir, la importancia o no de que los Parlamentos regionales participen en esta materia debería verse en términos positivos, como una aportación más y como una influencia sobre la decisión final ${ }^{45}$.

- El principal problema planteado es el tiempo del que disponen los Parlamentos nacionales para emitir el dictamen, seis semanas; este período ya se considera escaso, por lo que la problemática se agrava cuando se tiene que realizar necesariamente en ese período una consulta a los Parlamentos regionales.

- El Parlamento regional no tiene ningún voto, sólo sirve para ayudar a formar la voluntad del Parlamento nacional, o de una de sus Cámaras.

Esta participación de los Parlamentos regionales ha de quedar establecida de un modo más específico, para poder resolver las dudas que hoy se plantean:

44 Delgado-Iribarren García-Campero, M.: op. cit.; p. 787 y 788.

45 Alberti Rovira, E.: "Los parlamentos regionales en la Unión Europea», en la obra La Encrucijada constitucional de la Unión Europea, dirigida por GARCíA DE ENTERRÍA, E.: Civitas, Madrid, 2002, p. 360. 
- En el artículo 5 del protocolo se establece que sólo se podrá consultar a los Parlamentos regionales con competencias legislativas. Por tanto, si se trata de una materia que afecta a un parlamento que carece de dicha competencia, a priori no procede llevar a cabo esa consulta. Ello, y aunque no afecta a las Comunidades Autónomas españolas, nos parece absolutamente ilógico, pues no tiene en cuenta que la naturaleza jurídica de las competencias asumidas (legislativa o reglamentarias) no es, en buena doctrina, el único criterio determinante de la naturaleza política de las entidades descentralizadas, debiendo incluir a todas aquellas que, con independencia de su organización política específica (es decir, con la existencia o no de un Parlamento regional), pudiesen verse afectadas. No debemos olvidar que el hecho regional en la Unión Europea se manifiesta en muy diversas formas, y que la opinión dominante en los círculos comunitarios parece ser el rechazo de una categorización que suponga una diferencia entre varios tipos de regiones (regiones con o sin competencias legislativas).

- ¿Es posible que pese a que la regulación comunitaria establezca que se trata de una mera consulta, la legislación nacional lo convierta en obligatorio? La respuesta ha de ser necesariamente positiva, y para ello debe aparecer regulado en los respectivos Estatutos de Autonomía, norma institucional básica de las Comunidades Autónomas, como así se está realizando en los diferentes procesos de reforma estatutaria en España.

- ¿Con qué plazo se contaría para esa consulta? Ciertamente el plazo de seis semanas no puede ser alterado por la preceptiva consulta a los Parlamentos regionales. Por ello, debería establecerse un periodo de tiempo para que, dentro de esas seis semanas, dichos Parlamentos recibieran la misma información que los nacionales y elaborasen un informe que habrían de remitir a aquellos. A este respecto, se debe articular un sistema ágil en base al cual dentro de ese plazo de seis semanas, el Senado envíe, al mismo tiempo que recibe la información y documentación del órgano comunitario emisor, a las Asambleas Autonómicas las propuestas legislativas, éstas estudien su contenido, adopten eventualmente el acuerdo de denuncia de la subsidiariedad, lo envíen otra vez al Senado, siguiendo un procedimiento legislativo ágil y eficaz. Podría incluso proponerse que el plazo del que han de disponer los Parlamentos regionales para emitir su dictamen, quede legalmente establecido, y sea, por ejemplo de tres semanas. 
- En los Estados con un sistema bicameral, según lo establecido en el citado artículo 5, cada cámara puede optar por consultar a los Parlamentos regionales. A nuestro criterio, esta consulta debe realizarse únicamente por la Cámara territorial, en aquellos países en que esta exista, careciendo de sentido de que, en el caso español, fuese el Congreso de los Diputados el encargo de remitir y recibir los informes de los Parlamentos regiona$\operatorname{les}^{46}$.

- En el caso en el que se decida llevar a cabo la consulta, ¿debe consultarse a todos los Parlamentos regionales con competencias, o sólo a los que se encuentren más vinculados con la materia? En concreto, en el protocolo se establece que «incumbirá a cada Parlamento Nacional, cuando proceda...", por tanto es necesario saber el significado de estos términos ${ }^{47}$ :

- «incumbirá»; puede referirse sencillamente al órgano que debe efectuar la consulta, pero entendiendo que éste está obligado a trasladarla; o si, en estricto respeto al principio de autonomía, ofrece libertad al órgano estatal para realizar o no dicha consulta.

- "cuando proceda»; cuando tenga competencias.

Con respecto al control a posteriori, el último párrafo del artículo 7 del protocolo, en el que se hace referencia a la posibilidad de interponer este recurso por parte de los Parlamentos nacionales, establece que: "De conformidad con el mismo artículo de la Constitución, el Comité de las Regiones también podrá interponer recursos respecto de los actos legislativos europeos para cuya adopción la Constitución requiera su consulta", por tanto también los Parlamentos regionales, a través del Comité de las Regiones, pueden intervenir en este aspecto. Además, y como ya hemos apuntado, nada parece impedir que un número determinado de Parlamentos regionales pueda instar, incluso con carácter vinculante, y al igual que las Cámaras de los Parlamentos nacionales, la presentación de dicho recurso.

Asé pues, el sistema de alerta temprana, a no ser que las regulaciones internas lo modifiquen sustancialmente, no parece satisfacer las demandas de las regiones europeas. En definitiva, las regiones se

46 Albertí Rovira, E.: Las Comunidades Autónomas en la Unión Europea, CEPC, Madrid, 2005, p. 24 y ss.

47 Montilla Martos, J. A.: Las Comunidades Autónomas en la Unión Europea, CEPC, Madrid, 2005, p. 83. 
ven desilusionadas, ya que toda la esperanza puesta en la regulación del Protocolo con el fin de encauzar su participación en la Unión, se reduce a depender de los Parlamentos nacionales, lo que en la mayoría de los casos supone depender de un Senado que no tiene obligación de contar con ellas. La participación de los Parlamentos regionales es por tanto una cuestión interna de cada uno de los Estados miembros que cuenten con esa estructura compuesta. Nuestro sistema, pese a ser bicameral, es desequilibrado por el hecho de que el papel del Congreso es, a todos los efectos, y principalmente en el proceso legislativo, preponderante; por ello, y teniendo presente el papel que los Parlamentos regionales pueden llegar a desarrollar en este sistema podemos estimar que nos encontramos ante el momento adecuado para que se reconozca el papel más relevante que para este supuesto debería tener el Senado y los diferentes Parlamentos de las Comunidades Autónomas.

Actualmente, los Estatutos de Autonomía de las distintas Comunidades Autónomas no hacen alusión a la Unión Europea, salvo en lo que respecta a temas económicos y presupuestarios. Por lo tanto nos encontramos con otra laguna al respecto: ¿qué deberían estipular los Estatutos de Autonomía sobre ello?, ¿comienza a vislumbrarse algo en los nuevos proyectos de Estatuto que se están redactando en la actualidad?, ¿deben seguir todos ellos un criterio uniforme? En principio, podemos afirmar que sería conveniente que la Constitución española incluyese, si no la forma concreta de llevar a cabo esa participación regional, sí al menos el "principio de participación de las regiones", como lo hace la italiana. En cuanto a los actuales procesos de reforma estatutaria en curso, el tema esta siendo objeto de diferentes regulaciones normativas.

- El proyecto de reforma del País Vasco, denominado Plan Ibarretxe, que finalmente no fue admitido a trámite en el Congreso de los Diputados, establecía únicamente en su artículo 65 y siguientes que "...el Gobierno español habilitará los cauces precisos para posibilitar la participación activa del Gobierno Vasco en los diferentes procedimientos de toma de decisiones de las instituciones comunitarias en aquellos asuntos que afecten a sus competencias..." y que "... El Estado garantizará el acceso de las instituciones vascas al Tribunal Europeo de Justicia en tanto en cuanto no se encuentre previsto su acceso directo en la normativa europea."

- Por su parte, el Estatuto Valenciano, actualmente en tramitación en el Congreso de los Diputados, regula en su Título VI las "Relaciones con la Unión Europea» donde establece que la Comunidad 
valenciana, como región de la Unión Europea, sin perjuicio de la legislación del Estado, "participará en los mecanismos de control del principio de subsidiaridad previsto en el Derecho de las Unión Europea".

- El actual Proyecto de Reforma del Estatuto de Cataluña, ya admitido a trámite en el Congreso de los Diputados, recoge la cuestión de una forma mucho más pormenorizada en el Título $V$, "De las relaciones de la Generalidad con el Estado, con otras Comunidades Autónomas y con la Unión Europea, y de la Acción exterior de la Generalidad". En concreto establece que la Generalidad debe participar en los asuntos relacionados con la Unión Europea que afecten a las competencias o a los intereses de Cataluña y que el Parlamento puede establecer relaciones con el Parlamento Europeo en ámbitos de interés común (artículo 187.4 del Proyecto de reforma de Estatuto). Además, en su artículo 188 sobre la participación en el control de los principios de subsidiariedad y de proporcionalidad, establece que «el Parlamento debe ser consultado previamente a la emisión del dictamen de las Cortes Generales sobre las propuestas legislativas europeas, en el marco del procedimiento del control de los principios de subsidiariedad y de proporcionalidad que establece el derecho de la Unión Europea si dichas propuestas afectan a las competencias de la Generalidad". Por tanto, vemos cómo la posibilidad de consulta que se recoge en el Protocolo de Subsidiariedad puede quedar transformada en un deber si así se acuerda regular en la legislación interna de los Estados miembros y, en concreto para el caso español, mediante los estatutos de Autonomía de sus respectivas Comunidades Autónomas.

- Respecto a otras Comunidades Autónomas (Canarias, Andalucía, Baleares, etc.), la tramitación de reforma de sus respectivos estatutos, que actualmente se está llevando a cabo en sus Parlamentos regionales, también se prevé esta posibilidad de participación. 